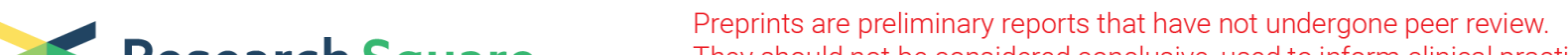 Research Square
They should not be considered conclusive, used to inform clinical practice,
or refenced by the media as validated information.
}

\section{Different regulation of PARP1, PARP2, PARP3 and TRPM2 genes expression in acute myeloid leukemia cells}

Paulina Gil-Kulik ( $\sim$ pgil.poczt@vp.pl )

Uniwersytet Medyczny w Lublinie https://orcid.org/0000-0003-3119-981X

\section{Ewa Dudzińska}

Uniwersytet Medyczny w Lublinie

\section{Elżbieta Radzikowska-Büchner}

Department of Plastic Surgery Saint Elizabeth Hospital

\section{Joanna Wawer}

Uniwersytet Medyczny w Lublinie

Mariusz Jojczuk

Uniwersytet Medyczny w Lublinie

\section{Adam Nogalski}

Uniwersytet Medyczny w Lublinie

\section{Genowefa Anna Wawer}

Uniwersytet Medyczny w Lublinie

\section{Marcin Feldo}

Uniwersytet Medyczny w Lublinie

\section{Wojciech Kocki}

Politechnika Lubelska

\section{Maria Cioch}

Uniwersytet Medyczny w Lublinie

\section{Anna Bogucka-Kocka}

Uniwersytet Medyczny w Lublinie

\section{Mansur Rahnama}

Uniwersytet Medyczny w Lublinie

Janusz Kocki

Uniwersytet Medyczny w Lublinie

\section{Research article}

Keywords: PARP1, PARP2, PARP3, TRPM2 gene expression, AML, hematopoietic stem cells 
Posted Date: December 16th, 2019

DOl: https://doi.org/10.21203/rs.2.19004/v1

License: (c) (i) This work is licensed under a Creative Commons Attribution 4.0 International License. Read Full License

Version of Record: A version of this preprint was published at BMC Cancer on May 18th, 2020. See the published version at https://doi.org/10.1186/s12885-020-06903-4. 


\section{Abstract}

Acute myeloid leukemia (AML) is a heterogenic lethal disorder characterized by the accumulation of abnormal myeloid progenitor cells in the bone marrow, which results in hematopoietic failure. Despite various efforts in detection and treatment, many patients with AML die of this cancer. That is why it is important to develop novel therapeutic options, employing strategic target genes involved in apoptosis and tumor progression. The aim of the study was to evaluate PARP1, PARP2, PARP3, and TRPM2 gene expression at the mRNA level in the cells of the hematopoietic system of the bone marrow in patients with acute myeloid leukemia, bone marrow collected from healthy patients, peripheral blood of healthy individuals, and hematopoietic stem cells from the peripheral blood after mobilization.

Results: The results found that the bone marrow cells of patients with acute myeloid leukemia (AML) show over expression of PARP1 and PARP2 genes and decreased TRPM2 gene expression. In the hematopoietic stem cells derived from the normal marrow and peripheral blood after mobilization, the opposite situation was observed, i.e. TRPM2 gene showed increased expression while PARP1 and PARP2 gene expression was reduced. We observed the positive correlations between PARP1, PARP2, PARP3, and TRPM2 genes expression in the group of mature mononuclear cells derived from the peripheral blood and in the group of bone marrow-derived cells. In AML cells significant correlations were not observed between the expression of the examined genes.

Conclusions: Our research suggests that in physiological conditions in the cells of the hematopoietic system there is mutual positive regulation of PARP1, PARP2, PARP3, and TRPM2 genes expression. PARP1, PARP2, and TRPM2 genes at mRNA level deregulate in acute myeloid leukemia cells.

\section{Introduction}

Acute myeloid leukemia ( $\mathrm{AML}$ ) is a heterogenic lethal disorder characterized by the accumulation of abnormal myeloid progenitor cells in the bone marrow which results in hematopoietic failure. A major contributing factor to the high mortality rate associated with acute myeloid leukemia is the development of resistance to chemotherapy [1]. Despite various efforts in detection and treatment, many patients with AML die of this cancer. That is why it is important to develop novel therapeutic options, employing strategic target genes involved in apoptosis and tumor progression [2].

Polymerases poly (ADP-ribose) PARP is a family of seventeen proteins that react with poly or mono ADPribosylation, and are involved in numerous cellular processes such as DNA repair, cell death, transcription, translation, cell proliferation, or cell response to oxidative stress. PARPs have the ability to modulate the transcriptional functions of both tumor suppressors and oncogenes, which affects the ability of PARP to elicit contextual proton and antineoplastic effects [3].

PARP1, PARP2, and PARP3 are involved in the repair of DNA damage. It is mainly for this reason it is recommended to use PARP inhibitors (PARPi) in the treatment of tumors, in particular those that do not 
have the ability to recombine (homologous recombination - HR) due to the mutations causing loss of BRCA1 or BRCA2 function. This phenomenon is referred to as synthetic lethality $[4,5,6]$.

In many types of tumors, elevated PARP1 mRNA is associated with poor prognosis and thus a shorter survival time. Increased expression of PARP1 has been demonstrated in various types of tumors, including breast cancer, soft tissue sarcomas, endometrial adenocarcinoma, gliomas, colorectal cancer, myelodysplastic syndrome, neuroma, malignant lymphoma, testicular cancer, ovarian cancer $[7,8,9,10$, 11]. PARP1 was also found in acute myeloid leukemia and is suggested to be an independent prognostic factor in AML $[9,10]$.

Hyperactivation of PARP pathway observed in tumors can be used to selectively kill tumor cells. PARPi treatment was shown to be effective in monotherapy and in combination therapies mainly in gynecological cancers, and researchers also suspect potential of PARP inhibitors involvement in acute myeloid leukemia $[9,12,13]$.

Recent studies show that PARP may also be involved in the epigenetic regulation maintaining stem cell pluripotency, and their expression is probably necessary for the proper differentiation of stem cells including hematopoietic stem cells. Some authors even suggest that PARP can be used to reprogram somatic stem cells towards induced pluripotent stem cell (iPSC) $[14,15,16,17,18]$.

Transient receptor potential (TRP) channels are cation channels associated with cancer. To date, TRPM members including TRPM2, 4, 5, 7 and 8 have also been proven to be associated with the proliferation and survival of cells. Among TRP channels, TRPM2 is expressed in many noncancerous cells, such as the brain and peripheral blood cells. Studies show that TRPM2 is associated with various types of cancers, too [19].

TRPM2 is a member of the TRP protein superfamily of ion channels that can be activated by ADP-ribose, $\beta-N A D, T N F-a$, and $\mathrm{H}_{2} \mathrm{O}_{2}$ which results in increased values of intracellular free calcium concentration ([Ca $\left.{ }^{2+}\right]_{i}$ ) [20]. TRPM2 is a non-selective cationic, $\mathrm{Ca}^{2+}$ - permeable pore, and contains a unique $\mathrm{C}$-terminal region exhibiting ADP-ribose (ADPR) hydrolase activity. The highest expression levels of TRPM2 are observed in the cells of neuronal origin and in the myeloid lineage [21].

Data suggest that TRPM2 channels function as 'death channels', because as a matter of fact, heterologous expression of TRPM2 in human embryonic kidney cells or A172 human glioblastoma cells facilitates oxidative stress-induced cell death. Furthermore, expression of TRPM2 has been demonstrated in several tumors such as hepatocellular carcinoma, prostate cancer, lymphoma, leukemia, and lung cancer cell lines in which TRPM2 reportedly may foster cell death [22]. TRPM2 is one ion channel that can be altered to increase apoptosis in cancer cells [23].

The aim of the study was to evaluate of PARP1, PARP2, PARP3 and TRPM2 gene expression at mRNA level in the cells of the hematopoietic system of the bone marrow in patients with acute myeloid 
leukemia, bone marrow from healthy patients, peripheral blood of healthy individuals, and hematopoietic stem cells from the peripheral blood after mobilization.

\section{Material}

The study comprised a group of 84 patients. The study group consisted of 53 patients hospitalized at the Department and Clinic of Hematooncology with Bone Marrow Transplantation, Medical University of Lublin, Poland, among them 14 patients with acute myeloid leukemia - samples of bone marrow were examined, and 39 patients in remission stage who had previously suffered from hematologic illnesses samples of hematopoietic stem cells from the peripheral blood which underwent mobilization were tested, 10 patients of the Chair and Clinic of Traumatic Surgery and Emergency Medicine, Medical University of Lublin. The patients had normal bone marrow sampled during hip replacement surgery, and 21 healthy volunteers from whom peripheral blood was collected. The study groups were similar in terms of age and sex of patients.

The research was carried out with the approval of the Local Bioethics Commission No KE0254/110/2012.

\section{Methods}

\section{Cell isolation.}

Mononuclear cells were isolated from the bone marrow and peripheral blood collected on EDTA anticoagulant by density gradient centrifugation using Histopaque-1077 reagent (Sigma, USA) and PBS reagent (Biomed, Poland).

Hematopoietic stem cells were isolated from peripheral blood on the fifth day after mobilization with granulocyte growth factor using a cell separator method. The procedure of stem cell separation was performed in the Department of Haematooncology and Bone Marrow Transplantation, Medical University of Lublin [24].

\section{RNA isolation.}

RNA was isolated from the samples obtained from blood and marrow mononuclears. Isolation of the total cellular mRNA was carried out by the modified method of Chomczyński and Sacchi [25] using TRIReagent (Sigma, USA), isopropanol (Sigma, USA), and chloroform (Sigma, USA). The concentration and purity of the isolated RNA was tested by spectrophotometry (NanoDrop 2000c).

\section{Reverse transcription reaction.}

A specific fragment of the analyzed gene was obtained by amplification using CDNA synthesized on the basis $1 \mu \mathrm{g}$ of isolated RNA using Reverse Transcriptase Kits (Applied Biosystem, USA) according to the manufacturer's recommendations. 


\section{qPCR reaction.}

The analysis of gene expression was performed by real-time PCR on StepOnePlus (Applied Biosystems) using TaqMan probes (Applied Biosystems, USA) for endogenous control gene: GAPDH. Hs99999905_m1; for TRPM2 gene: Hs01066071_m1; for PARP1 gene: Hs00242302_m1 for PARP2 gene: Hs00193931_m1 for PARP3 test gene: Hs00193946_m1. The level of relative gene expression was calculated from the formula $\mathrm{RQ}=2^{-\Delta \Delta \mathrm{Ct}}[26]$. Data analysis was done by Expression Suite Software 1.0.3. (Life Technologies). Detailed procedures for the cells isolation, reverse transcription and real time PCR reactions have been described in our previous work, where we showed that the studied hematopoietic stem cells of peripheral blood and healthy bone marrow cells express the high level of BIRC5 gene expression, which confirms native nature of the tested hematopoetic stem cells [27].

\section{Statistical analysis.}

Statistical analysis was done by Statistica 13 software. To examine the differences between the study groups, ANOVA Kruskal-Wallis Test was applied and the Spearman's correlation test, $p<0.05$ was assumed statistically significant.

\section{Results}

The results found PARP1, PARP2, PARP3, and TRPM2 genes were expressed in all examined cells. The highest PARP1 gene expression was found in acute myeloid leukemia cells $(\log R Q=0.335 \pm 0.136)$, while the lowest PARP1 gene expression was detected in the group of hematopoietic stem cells collected from the peripheral blood after mobilization ( $\log R Q=-0.266 \pm 0.057$ ). A statistically significant difference in the expression of PARP1 between AML group and PBSC $\left(p=0.001^{*}\right)$ was demonstrated. The analysis of PARP2 gene expression produced similar results, the highest expression was detected in AML group $(\operatorname{logRQ}=0.509 \pm 0.197)$, while PBSC group showed the lowest expression $(\log R Q=-0.262 \pm 0.051)$, the difference was statistically significant $\left(p=0.003^{*}\right)$. Statistical analysis of PARP3 gene expression in the studied groups did not show significant differences. TRPM2 gene expression was significantly different in the study groups. The highest expression was recorded in the bone marrow cells (logRQ $=0.864 \pm$ $0.117)$, while the lowest in the peripheral blood cells $(\log R Q=-0.653 \pm 0.216)$, and acute myeloid leukemia $(\operatorname{logRQ}=-0.460 \pm 0.313)$. There were significant differences in TRPM2 gene expression between BM and AML groups $\left(p=0.016^{\star}\right), B M$ and PBSC $\left(p=0.033^{*}\right)$, and BM and PBMC groups $\left(p=0.025^{\star}\right)$ (Fig. 1 , Table 1). 
Table 1

Mean PARP1, PARP2, PARP3, and TRPM2 gene expression (logRQ \pm SE) in tested groups, * ANOVA Kruskal-Wallis Test

\begin{tabular}{|c|c|c|c|c|c|c|c|c|}
\hline \multicolumn{5}{|c|}{ Mean gene expression in tested group } & \multicolumn{4}{|l|}{ p-value } \\
\hline Gene & Group & $\mathrm{N}$ & Mean logRQ & SE & AML & PBMC & PBSC & BM \\
\hline \multirow[t]{4}{*}{ PARP1 } & AML & 14 & 0.351 & 0.136 & & 0.156 & $0.001^{\star}$ & 0.455 \\
\hline & PBMC & 21 & -0.015 & 0.057 & 0.156 & & 0.968 & 0.899 \\
\hline & PBSC & 39 & -0.266 & 0.035 & $0.001^{*}$ & 0.968 & & 0.379 \\
\hline & BM & 10 & 0.064 & 0.069 & 0.455 & 0.899 & 0.379 & \\
\hline \multirow[t]{4}{*}{ PARP2 } & AML & 14 & 0.509 & 0.197 & & 0.163 & $0.003^{\star}$ & 0.224 \\
\hline & PBMC & 21 & -0.104 & 0.051 & 0.163 & & 0.992 & 0.988 \\
\hline & PBSC & 39 & -0.262 & 0.051 & $0.003^{*}$ & 0.992 & & 0.799 \\
\hline & BM & 10 & 0.017 & 0.127 & 0.224 & 0.988 & 0.799 & \\
\hline \multirow[t]{4}{*}{ PARP3 } & AML & 14 & 0.048 & 0.123 & & 0.858 & 0.700 & 0.973 \\
\hline & PBMC & 21 & -0.128 & 0.056 & 0.858 & & 1.000 & 0.989 \\
\hline & PBSC & 39 & -0.169 & 0.042 & 0.700 & 1.000 & & 0.990 \\
\hline & BM & 10 & -0.061 & 0.093 & 0.973 & 0.989 & 0.990 & \\
\hline \multirow[t]{4}{*}{ TRPM2 } & AML & 14 & -0.460 & 0.313 & & 0.997 & 0.841 & $0.016^{*}$ \\
\hline & PBMC & 21 & -0.653 & 0.216 & 0.997 & & 0.828 & $0.025^{\star}$ \\
\hline & PBSC & 39 & -0.079 & 0.088 & 0.841 & 0.828 & & $0.033^{\star}$ \\
\hline & BM & 10 & 0.864 & 0.171 & $0.016^{*}$ & $0.025^{\star}$ & $0.033^{*}$ & \\
\hline
\end{tabular}

Statistically significant correlations between the expression of the examined genes were demonstrated. In the group of stem cells collected from the peripheral blood after mobilization very strong positive correlations were found between the expression of all tested genes: PARP1 and PARP2 $(r=0.965 p<$ 0.05), PARP1 and PARP3 $(r=0.950 p<0.05)$, PARP1 and TRPM2 $(r=0.890 p<0.05)$, PARP2 and PARP3 $(r$ $=0.991 p<0.05)$, PARP2 and TRPM2 $(r=0.911 p<0.05)$, PARP3 and TRPM2 $(r=0.951 p<0.05)$. Also in the group of bone marrow-derived stem cells, statistically significant positive correlations were observed between the expression of all tested genes: PARP1 and PARP2 $(r=0.929 p<0.05)$, PARP1 and PARP3 $(r=$ $0.964 p<0.05)$, PARP1 and TRPM2 $(r=0.607 p<0.05)$, PARP2 and PARP3 $(r=0.821 p<0.05)$, PARP2 and TRPM2 $(r=0.571 p<0.05)$, PARP3 and TRPM2 $(r=0.536 p<0.05)$. In the group of hematopoetic stem cells derived from the peripheral blood after mobilization there was a statistically significant positive correlation between PARP1 and PARP2 gene expression $(r=0.778 p<0.05)$, PARP1 and PARP3 $(r=0.693$ 
$p<0.05)$, and PARP3 and PARP2 $(r=0.820 p<0.05)$, PARP3 and TRPM2 $(r=0.398 p<0.05)$. In acute myelogenous leukemia group, there were no statistically significant relationships between the expression of the examined genes (Table 2).

Table 2

Correlation of PARP1, PARP2, PARP3 and TRAPM2 gene expression in tested group. ${ }^{*} p<0.05$, Spearman's correlation test

\begin{tabular}{|c|c|c|c|c|c|}
\hline Gene & Group & logRQ PARP1 & logRQ PARP2 & logRQ PARP3 & $\operatorname{logRQ}$ TRPM2 \\
\hline logRQ PARP1 & \multirow[t]{4}{*}{ AML } & & 0.489 & 0.541 & -0.564 \\
\hline logRQ PARP2 & & 0.489 & & 0.301 & -0.075 \\
\hline logRQ PARP3 & & 0.541 & 0.301 & & -0.201 \\
\hline $\operatorname{logRQ}$ TRPM2 & & -0.564 & -0.075 & -0.201 & \\
\hline logRQ PARP1 & \multirow[t]{4}{*}{ PBMC } & & $0.965^{\star}$ & $0.950 *$ & $0.890^{\star}$ \\
\hline logRQ PARP2 & & $0.965^{\star}$ & & $0.991^{*}$ & $0.911^{*}$ \\
\hline logRQ PARP3 & & $0.950 *$ & $0.991^{*}$ & & $0.951^{*}$ \\
\hline logRQ TRPM2 & & $0.890 *$ & $0.911^{*}$ & $0.951^{*}$ & \\
\hline logRQ PARP1 & \multirow[t]{4}{*}{ PBSC } & & $0.778^{*}$ & $0.693^{*}$ & 0.284 \\
\hline logRQ PARP2 & & $0.778^{\star}$ & & $0.820 *$ & 0.236 \\
\hline logRQ PARP3 & & $0.693^{*}$ & $0.820 *$ & & $0.398^{*}$ \\
\hline logRQ TRPM2 & & 0.284 & 0.236 & $0.398^{*}$ & \\
\hline logRQ PARP1 & \multirow[t]{4}{*}{ BM } & & $0.929 *$ & $0.964^{*}$ & $0.607 *$ \\
\hline logRQ PARP2 & & $0.929 *$ & & $0.821^{*}$ & $0.571^{\star}$ \\
\hline logRQ PARP3 & & $0.964^{\star}$ & $0.821^{\star}$ & & $0.536^{\star}$ \\
\hline logRQ TRPM2 & & $0.607 *$ & $0.571^{\star}$ & $0.536^{*}$ & \\
\hline
\end{tabular}

\section{Discussion}

Observed by us positive correlations between PARP1, PARP2, PARP3, and TRPM2 genes expression in the group of mature mononuclear cells derived from the peripheral blood and in the group of bone marrowderived stem cells suggest that in physiological state there is mutual positive regulation of PARPs and TRPM2 genes expression. In the bone marrow cells of the patients with acute myelogenous leukemia, significant correlations were not observed between the expression of the examined genes. Our research suggests that there is a different regulation of PARP1, PARP2, PARP3, and TRPM2 genes expression in acute myelogenous leukemia cells. 
Interestingly, the bone marrow cells of patients with acute myelogenous leukemia show over expression of PARP1 and PARP2 genes and decreased TRPM2 gene expression.

In the hematopoietic stem cells derived from the normal marrow and peripheral blood after mobilization, the opposite situation was observed, i.e. TRPM2 gene showed increased expression while PARP1 and PARP2 gene expression was reduced. Our studies may suggest disrupted signaling between TRPM2 and PARP genes in cancer cells.

Similarly, the study by Zeng et al. [20] showed that knocking down TRPM2 increased PARP activity in prostate cancer cells through a unresolved mechanism [20]. In recent years, scientists have devoted much attention to the role of TRP channels in cancer. Among other things, it has been shown that TRPM2 is involved in cell migration and cell death, which are the key processes of cancer cell death [28]. The results of the studies by Zeng et al. [20] showed that in non-cancerous cells, TRPM2 proteins are mainly located at the plasma membrane where they mediate sodium and calcium influx on oxidative stimulation. Cation influxes may lead to membrane depolarization and changes in calcium homeostasis that can lead to programed cell death. In cancer cells, the role of TRPM2 as a plasma membrane ion channel is less important because of the internalization and nuclear localization of TRPM2. Numerous TRPM2 proteins are translocated into the nucleus where they may have an important enzymatic function related to cancer cell proliferation [20].

The cited studies also confirm our analyses in which we showed that in tumor cells TRPM2 gene expression is significantly decreased, whereas PARP1 and PARP2 expression is significantly increased, which may indicate that TRPM2 gene loses its function in tumor cells. In addition, we have shown that in the physiological state there is a positive relationship between PARP1, PARP2 and TRPM2, which is disturbed in cancer cells.

Correct regulation between the examined genes is extremely unimportant in the context of cell functioning, and its dysregulation may block apoptotic cell death, affect the progression of the cell cycle and increase cell proliferation as well as increase the possibility of DNA repair by overexpressing PARP. On the one hand, the activity of polymerase poli(ADP-ribose) depends on the intracellular calcium concentration, on the other hand polymers of (ADP-ribose) synthesized by PARP1, PARP2 and PARP3 stimulate TRPM2 in the normal cells [20].

The researchers observed that the expression of TRPM2 in AML subgroups is the higher the more differentiated AML cells are [21]. Klumpp et al. demonstrated that TRPM2 plays a key role in response to DNA damage in leukemic T lymphocytes. The researchers argue that irradiated Jurkat cells use TRPM2 channels to control cell cycle arrest in the G2/M phase [22]. Sumoza-Toledo et al. have demonstrated that the low TRPM2 expression may be used to predict adverse prognosis in ER-HER + breast cancer.

According to the researchers, TRPM2 is a promising biomarker of aggressiveness for breast cancer, and a potential target for new therapies [29]. TRPM2 channel has been identified as playing an important role in several types of cancers [30] including breast cancer, neuroblastoma, prostate cancer, head and neck cancer, melanoma [23], and colorectal cancer [31, 32, 33]. Potential TRPM2 involvement was confirmed in 
cell proliferation, facilitation of cell survival, prostate cancer, melanoma, genomic stability of breast cancer cells, promotion, survival and metastases in the head and neck [19]. The researchers observed that after TRPM2 silencing, the level of DNA damage in breast cancer cells was significantly increased, which was not observed in non-cancer breast cells after similar therapy [33]. So we speculate that therapy directed simultaneously at TRPM2 and PARPs would cause the cancer cells death as a result of damage accumulation and the inability to DNA repair.

Many studies indicate that TRPM2 is an ion channel that is modulated, and that can be altered to increase apoptosis in cancer cells including acute leukemia cells. Yanamandra et al. [1] identified molecular mechanisms by which tipifarnib produces cell death in AML and multiple myeloma cell lines (U937 and 8226 respectively). Several plasma membrane calcium channels have been identified in U937 cells that may potentially account for the elevated $\left[\mathrm{Ca}^{2+}\right]_{I}$, and concomitant cell death in response to tipifarnib application reported by Yanamandra. They include TRPM2, TRPM7, and store-operated calcium channels. In U937 cells, the activation of TRPM2 with either $\mathrm{H}_{2} \mathrm{O}_{2}$ or tumor necrosis factor-a increased cleavage of caspase-8, caspase-9, caspase-3, caspase-7, PARP, and consequently cell death was enhanced in a $\left[\mathrm{Ca}^{2+}\right][1]$. Based on the conducted studies, we noted that the bone marrow and blood cell samples of the patients with acute leukemia showed statistically significantly lower mean TRPM2 gene expression compared to the normal bone marrow. Reduced expression of TRPM2 gene may be associated with disordered apoptotic cycle in cancerous cells.

Our results show also increased expression of PARP1 and PARP2 gene in AML cells. In many studies PARP1 expression was found to be significantly increased in several malignant tissues, e.g. breast, uterine, lung, ovarian. Within breast infiltrating ductal carcinoma samples tested, mean PARP1 expression was significantly higher compared to normal breast tissue [34].

The latest data also confirm that PARP1 was highly expressed in cytogenetically normal AML patients and AML cell lines compared to normal bone marrow cells. It may indicate that PARP1 plays a critical role in the development of AML [4]. Research by Fonfria et al. [35] confirms the hypothesis that PARP enzyme activity is a central component of the pathway linking oxidative stress with TRPM2 activation [35]. Intracellular $\mathrm{Ca}^{2+}$ regulation has a crucial role in tumorigenesis, including cell replication and apoptosis. Nuclear expression of TRPM2 may also influence nuclear $\mathrm{Ca}^{2+}$ concentration [20].

In our studies we showed that in the bone marrow cells of patients with acute myeloid leukemia, PARP1 and PARP2 genes are overexpressed and TRPM2 gene is down-regulated, which may suggest disturbed signaling between these genes. The modified TRPM2 function may suggest disturbed signaling between TRPM2 and PARPs at the transcript level, which increases the expression of polymerases. Numerous studies have reported that overexpression of PARP genes in turn is associated with uncontrolled cell proliferation, increased DNA repair ability, and increased telomerase activity which is associated with cell immortalization [36]. 
The demonstrated in our study positive correlations between PARP1, PARP2, PARP3, and TRPM2 gene expression in the group of PBMC and in the group of BM cells suggest that in the physiological state there is mutual positive regulation of PARP family members and TRPM2 gene expression. In the bone marrow cells from the patients with acute myelogenous leukemia, significant relationships between the expression of the test genes were not observed. Our research suggests that there is a different regulation of PARP1, PARP2, PARP3, and TRPM2 gene expression in acute myelogenous leukemia cells. We speculate that correct signaling between TRPM2 and PARPs is essential for physiology, and its loss may affect the development of acute leukemia. Regulation of PARP1, PARP2, PARP3, and TRPM2 genes expression may provide a new therapeutic strategy against AML.

Therefore, there is a need for further research on the mutual regulation of PARP1, PARP2, PARP3, and TRPM2 gene expression in AML.

\section{Conclusions}

Our research suggests that in physiological conditions the cells of the hematopoietic system exhibit mutual positive regulation of PARP1, PARP2, PARP3, and TRPM2 gene expression. In acute myelogenous leukemia cells, PARP1, PARP2, and TRPM2 gene mRNA levels deregulate.

\section{Declarations}

\section{Authors' Contributions:}

"conceptualization, P.G.-K. and J.K.; methodology, P.G.-K. and J.K. software, P.G.-K.; and W.K.; validation, M.C.; A.B.-K., M.R. and J.K.; formal analysis, P.G.-K..; investigation, P.G.-K.; E.D.; E.R.-B.; J.W.; M.F.; resources, M.F; M.J.; A.N.; M.C.; M.R. and J.K.; data curation, P.G.-K. and J.K..; writing-original draft preparation, P.G.-K. and E.D.; writing-review and editing, P.G.-K.; E.D.; E.R.-B., J.W.; G.A.W.; M.F.; W.K.; M.J; A.N. and J.K. visualization, P.G-K. and E.D. supervision, M.C., A.B.-K., M.R. and J.K. ; project administration, P.G.-K and J.K. funding acquisition, J.K.."

\section{Funding}

This study was supported in part by funds from the project "The equipment of innovative laboratories doing research on new medicines used in the therapy of civilization and neoplastic diseases" within the Operational Program Development of Eastern Poland 2007-2013, Priority Axis I Modern Economy, Operations I.3 Innovation Promotion and and in part by National Centre for Research and Development grant STRATEGMED III (STRATEGMED3/303570/7/NCBR/2017) to JK.

\section{Data availability:}

The data used to support the findings of this study are included within the article.

\section{Ethics approval and consent to participate}


The research was carried out with the approval of the Local Bioethics Commission No KE0254/110/2012.

\section{Consent for publication}

Not applicable. This manuscript does not contain data from any individual

person.

\section{Competing interests}

The authors declare that they have no competing interests.

\section{Corresponding author}

Paulina Gil-Kulik e-mail: paulina.gil-kulik@umlub.pl

\section{Author details}

${ }^{1}$ Department of Clinical Genetics, Medical University of Lublin, 11 Radziwillowska Str., 20-080 Lublin, Poland; paulina.gil-kulik@umlub.pl (P.G.-K.); jwaawer@gmail.com (J.W.); janusz.kocki@umlub.pl (J.K.)

${ }^{2}$ Department of Public Health, Faculty of Health Sciences, Medical University of Lublin, 1 Chodźki Str., 20093 Lublin,Poland; ewa.dudzinska@umlub.pl

${ }^{3}$ Department of Plastic Surgery, Saint Elizabeth's Hospital, 1 Goszczynskiego Str., 02-616 Warsaw, Poland; eradzikowska@radzikowskaclinic.pl

${ }^{4}$ Chair and Department of Trauma Surgery and Emergency Medicine, Medical University of Lublin, 16 Staszica Str., 20-081 Lublin, Poland; mariusz.jojczuk@umlub.pl (M.J.); adam.nogalski@umlub.pl (A.N.)

${ }^{5}$ Department of Foreign Languages Medical University of Lublin, 4 Jaczewskiego Str., 20-090 Lublin, Poland; genowefa.wawer@umlub.pl

${ }^{6}$ Chair and Department of Vascular Surgery and Angiology, Medical University of Lublin, 11 Staszica Str., 20-081 Lublin, Poland; marcin.feldo@umlub.pl

${ }^{7}$ Department of Architecture and Urban Planning, University of Technology, 40 Nadbystrzycka Str., 20-618 Lublin, Poland; w.kocki@pollub.pl

${ }^{8}$ Chair and Department of Hematooncology and Bone Marrow Transplantation, Medical University of Lublin, 11 Staszica Str., 20-081 Lublin, Poland; maria.cioch@umlub.pl

${ }^{9}$ Chair and Department of Biology and Genetics, Medical University of Lublin, 4a Chodźki Str., 20-093 Lublin, Poland; anna.kocka@umlub.pl 
${ }^{10}$ Chair and Department of Dental Surgery Medical University of Lublin, 7 Karmelicka Str., 20-081 Lublin, Poland; mansur.rahnama@umlub.pl

\section{Abbreviations}

PBMC: peripheral blood mononuclear cells of healthy patients

BM: bone marrow cells of healthy patients

AML: bone marrow cells of acute myeloid leukemia patients

PBSC: peripheral blood stem cells after mobilization of patient in remission

\section{References}

1. Yanamandra N, Buzzeo RW, Gabriel M, Hazlehurst LA, Mari Y, Beaupre DM, Cuevas J. Tipifarnibinduced apoptosis in acute myeloid leukemia and multiple myeloma cells depends on $\mathrm{Ca} 2+$ influx through plasma membrane Ca2+ channels. J Pharmacol Exp Ther. 2011;337(3):636-43. doi: 10.1124/jpet.110.172809. Epub 2011 Mar 4.

2. Wang $X$, Liu R, Wang $Y$, Cai H, Zhang L. Effects of down-regulation of clusterin by small interference RNA on human acute myeloid leukemia cells. Int J Clin Exp Med. 2015;8(11):20925-31. eCollection 2015.

3. Schiewer MJ, Knudsen KE. Transcriptional Roles of PARP1 in Cancer. Mol Cancer Res. 2014; 12(8): 1069-1080.

4. Li X, Li C, Jin J, Wang J, Huang J, Ma Z, Huang X, He X, Zhou Y, Xu Y, Yu M, Huang S, Yan X, Li F, Pan J, Wang Y, Yu Y, Jin J. High PARP-1 expression predicts poor survival in acute myeloid leukemia and PARP-1 inhibitor and SAHA-bendamustine hybrid inhibitor combination treatment synergistically enhances anti-tumor effects. EBioMedicine. 38:47-56. doi: 10.1016/j.ebiom.2018.11.025. Epub 2018 Nov 22. PubMed PMID: 30472087; PubMed Central PMCID: PMC6306376.

5. Ford AL, Lee JM. Climbing STAIRs towards clinical trials with a novel PARP-1 inhibitor for the treatment of ischemic stroke. Brain Res. 2011; 1410: 120-121.

6. Ghosh R, Roy S, Kamyab J, Danzter F, Francoa S. Common and Unique Genetic Interactions of the Poly(ADP-ribose) Polymerases PARP1 and PARP2 with DNA Double-Strand Break Repair Pathways. DNA Repair (Amst). 2016; 45: 56-62.

7. Schiewer MJ, Mandigo AC, Gordon N, Huang F, Gaur S, de Leeuw R, Zhao SG, Evans J, Han S, Parsons T, Birbe R, McCue P, McNair C, Chand SN, Cendon-Florez Y, Gallagher P, McCann JJ, Poudel Neupane N, Shafi AA, Dylgjeri E, Brand LJ, Visakorpi T, Raj GV, Lallas CD, Trabulsi EJ, Gomella LG, Dicker AP, Kelly WK, Leiby BE, Knudsen B, Feng FY, Knudsen KE. 11 PARP-1 regulates DNA repair factor availability. EMBO Mol Med. 2018; 10(12): 8816. 
8. Diamantopoulos P, Zervakis K, Zervakis P, Sofotasiou M, Vassilakopoulos T, Kotsianidis I, Symeonidis A, Pappa V Galanopoulos A, Solomou E, Kodandreopoulou E, Papadopoulou V, Korkolopoulou P, Mantzourani, Kyriakakis G, Viniou NA. Poly (ADP-ribose) polymerase 1 mRNA levels strongly correlate with the prognosis of myelodysplastic syndromes. Blood Cancer J. 2017; 7(2): 533. doi: $10.1038 /$ bcj.2016.127.

9. Pashaiefar H, Yaghmaie M, Tavakkoly-Bazzaz J, Ghaffari SH, Alimoghaddam K, Momeny M, Izadi P, Izadifard M, Kasaeian A, Ghavamzadeh A. PARP-1 Overexpression as an Independent Prognostic Factor in Adult Non-M3 Acute Myeloid Leukemia. Genet Test Mol Biomarkers. 2018; 22(6): 343-349.

10. Li N, Wang Y, Deng W, Lin SH. Poly (ADP-Ribose) Polymerases (PARPs) and PARP Inhibitor-Targeted Therapeutics. Anticancer Agents Med Chem. 2018; 9: doi: 10.2174/1871520618666181109164645.

11. Dudzińska E, Gryzińska M, Ognik K, Krauze M, Listos P. Non-specific inflammatory bowel disease and the risk of tumour growth. Med.Wet. 2018; 74(4): 228-232. DOI: 10.21521/mw.6048.

12. Dellomo AJ, Baer MR, Rassool FV.Partnering with PARP inhibitors in acute myeloid leukemia with FLT3-ITD. Cancer Lett. 2019 Jul 10;454:171-178. doi: 10.1016/j.canlet.2019.03.048. Epub 2019 Apr 4.

13. Faraoni I, Giansanti M, Voso MT, Lo-Coco F, Graziani G. Targeting ADP-ribosylation by PARP inhibitors in acute myeloid leukaemia and related disorders. Biochem Pharmacol. 2019 Apr 24. pii: S0006-2952(19)30154-6. doi: 10.1016/j.bcp.2019.04.019.

14. Chiou SH, Jiang BH, Yu YL, Chou SJ, Tsai PH, Chang WC, Chen LK, Chen LH, Chien Y, Chiou GY. Poly(ADP-ribose) polymerase 1 regulates nuclear reprogramming and promotes iPSC generation without c-Myc. J Exp Med. 2013; 210(1): 85-98.

15. Doege CA, Inoue K, Yamashita T, Rhee DB, Travis S, Fujita R, Guarnieri P, Bhagat G, Vanti WB, Shih A, Levine RL, Nik S, Chen El, Abeliovich A. Early-stage epigenetic modification during somatic cell reprogramming by Parp1 and Tet2. Nature. 2012; 488(7413): 652-655.

16. Farrés J, Llacuna L, Martin-Caballero J, Martinez C, Lozano JJ, Ampurdanes C, Lopez-Contreras AJ, Florensa L, Navarro J, Ottina E, Dantzer F, Schreiber V, Villunger A, Fernandez-Capetillo O, Yelamos J. PARP-2 sustains erythropoiesis in mice by limiting replicative stress in erythroid progenitors. Cell Death Differ. 2015; 22(7): 1144-1157.

17. Jiang BH, Tseng WL, Li HY, Wang ML, Chang YL, Sung YJ, Chiou SH. Poly(ADP-Ribose) Polymerase: Cellular Pluripotency, Reprogramming, and Tumorogenesis. Int J Mol Sci. 2015; 16(7): 15531-15545.

18. Roper SJ, Chrysanthou S, Senner CE, Sienerth A, Gnan S, Murray A, Masutani M, Latos P, Hemberger M. ADP-ribosyltransferases Parp1 and Parp7 safe guard pluripotency of ES cells. Nucleic Acids Res. 2014; 42(14): 8914-8927.

19. Zhao L, Xu W, Xu, Z, Qi C.Y, Li Y, Cheng J., Liu L., Wu Y., Gao J., Ye J.. The overexpressed functional transient receptor potential channel TRPM2 in oral squamous cell carcinoma. Scientific Reports 2016 volume 6, Article number: 38471

20. Zeng X, Sikka SC, Huang L, Sun C, Xu C, Jia D, Abdel-Mageed AB, Pottle JE, Taylor JT, Li M. Novel role for the transient receptor potential channel TRPM2 in prostate cancer cell proliferation. Prostate 
Cancer Prostatic Dis. 2010;13(2):195-201.

21. Haladyna JN, Pastuer T, Riedel SS, Perraud AL, Bernt KM. Transient potential receptor melastatin-2 (Trpm2) does not influence murine MLL-AF9-driven AML leukemogenesis or in vitro response to chemotherapy. Exp Hematol. 2016;44(7):596-602.e3.

22. Klumpp D, Misovic M, Szteyn K, Shumilina E, Rudner J, Huber SM. Targeting TRPM2 Channels Impairs Radiation-Induced Cell Cycle Arrest and Fosters Cell Death of T Cell Leukemia Cells in a Bcl2-Dependent Manner. Oxidative Medicine and Cellular Longevity. Volume 2016, Article ID 8026702, 14 pages

23. Blake SD, Tweed MC, McKamey SG, Koh DW. Transient receptor potential, Melastatin-2 (TRPM2) blockade: perspectives on potential novel clinical utility in cancer. Translational Cancer Research 2017, Vol 6, Supplement 2

24. H. Borowska, P. Klimek and M. Cioch, "The obtaining of peripheral blood stem cells and evaluation of its viability in the apheresis product before and after cryopreservation,"Journal of Laboratory Diagnostics, 50,3, pp.249-254, 2014

25. Chomczynski P, Sacchi N. Single-Step Method of Isolation by Acid Guanidinium Thiocyanate- PhenolChloroform Extraction. Anal Biochem. 1987;162:156-9.

26. K.J. Livak and T.D. Schmittgen," Analysis of Relative Gene Expression Data Using RealTime Quantitative PCR and the 2- $\triangle \triangle C T$ Method," METHODS,"; 25, pp.402-8, 2011.

27. Gil-Kulik P, Krzyżanowski A, Dudzińska E, Karwat J, Chomik P, Świstowska M, Kondracka A, Kwaśniewska A, Cioch M, Jojczuk J, Nogalski A, Kocki J. Potential involvement of BIRC5 in maintaining pluripotency and cell differentiation of human stem cells. Oxidative Medicine and Cellular Longevity [online] 2018 vol. 2018, art. ID 8727925.

28. Sumoza-Toledo A, Penner R. TRPM2: a multifunctional ion channel for calcium signalling. J Physiol. 2011;589(Pt 7):1515-25.

29. Sumoza-Toledo A, Espinoza-Gabriel MI, Montiel-Condado D. Evaluation of the TRPM2 channel as a biomarker in breast cancer using public databases analysis. Bol Med Hosp Infant Mex. 2016;73(6):397-404

30. Miller BA. TRPM2 in Cancer. Cell Calcium. 2019 Mar 6;80:8-17. doi: 10.1016/j.ceca.2019.03.002.

31. Ibrahim S, Dakik H, Vandier C, Chautard R, Paintaud G, Mazurier F, Lecomte T, Guéguinou M, Raoul W. Expression Profiling of Calcium Channels and Calcium-Activated Potassium Channels in Colorectal Cancer. Cancers (Basel). 2019 Apr 19;11(4). pii: E561.

32. Dudzińska E, Gryzinska M, Ognik K, Gil-Kulik P, Kocki J, Oxidative Stress and Effect of Treatment on the Oxidation Product Decomposition Processes in IBD, Oxidative Medicine and Cellular Longevity, vol. 2018, Article ID 7918261, 7 pages, 2018. https://doi.org/10.1155/2018/7918261.

33. Hopkins MM, Feng X, Liu M, Parker LP, Koh DW. Inhibition of the transient receptor potential melastatin-2 channel causes increased DNA damage and decreased proliferation in breast adenocarcinoma cells. Int J Oncol. 2015;46(5):2267-76. 
34. Ossovskaya V, Koo IC, Kaldjian EP, Alvares C, Sherman BM. Upregulation of Poly (ADP-Ribose) Polymerase-1 (PARP1) in Triple-Negative Breast Cancer and Other Primary Human Tumor Types. Genes Cancer. 2010;1(8):812-821. doi:10.1177/1947601910383418

35. Fonfria E, Marshall IC, Benham CD, Boyfield I, Brown JD, Hill K, Hughes JP, Skaper SD, McNulty S. TRPM2 channel opening in response to oxidative stress is dependent on activation of poly(ADPribose) polymerase. Br J Pharmacol. 2004 Sep;143(1):186-92. doi: 10.1038/sj.bjp.0705914. Epub 2004 Aug 9. PubMed PMID: 15302683; PubMed Central PMCID: PMC1575275.

36. Ngo G, Hyatt S, Grimstead J, Jones R, Hendrickson E, Pepper C, Baird D. PARP inhibition prevents escape from a telomere-driven crisis and inhibits cell immortalisation. Oncotarget. 2018 Dec 25;9(

\section{Tables}

Table 1

\begin{tabular}{|c|c|c|c|c|c|c|c|c|}
\hline \multicolumn{5}{|c|}{ Mean gene expression in tested group } & \multicolumn{4}{|c|}{$p$-value } \\
\hline Gene & Group & $\mathbf{N}$ & Mean $\log R Q$ & SE & AML & PBMC & PBSC & BM \\
\hline \multirow[t]{4}{*}{$P A R P 1$} & AML & 14 & 0.351 & 0.136 & & 0.156 & $0.001 *$ & 0.455 \\
\hline & PBMC & 21 & -0.015 & 0.057 & 0.156 & & 0.968 & 0.899 \\
\hline & PBSC & 39 & -0.266 & 0.035 & $0.001 *$ & 0.968 & & 0.379 \\
\hline & $\mathrm{BM}$ & 10 & 0.064 & 0.069 & 0.455 & 0.899 & 0.379 & \\
\hline \multirow[t]{4}{*}{$P A R P 2$} & AML & 14 & 0.509 & 0.197 & & 0.163 & $0.003 *$ & 0.224 \\
\hline & PBMC & 21 & -0.104 & 0.051 & 0.163 & & 0.992 & 0.988 \\
\hline & PBSC & 39 & -0.262 & 0.051 & $0.003^{*}$ & 0.992 & & 0.799 \\
\hline & $\mathrm{BM}$ & 10 & 0.017 & 0.127 & 0.224 & 0.988 & 0.799 & \\
\hline \multirow[t]{4}{*}{$P A R P 3$} & AML & 14 & 0.048 & 0.123 & & 0.858 & 0.700 & 0.973 \\
\hline & PBMC & 21 & -0.128 & 0.056 & 0.858 & & 1.000 & 0.989 \\
\hline & PBSC & 39 & -0.169 & 0.042 & 0.700 & 1.000 & & 0.990 \\
\hline & $\mathrm{BM}$ & 10 & -0.061 & 0.093 & 0.973 & 0.989 & 0.990 & \\
\hline \multirow[t]{4}{*}{ TRPM2 } & AML & 14 & -0.460 & 0.313 & & 0.997 & 0.841 & $0.016^{*}$ \\
\hline & PBMC & 21 & -0.653 & 0.216 & 0.997 & & 0.828 & $0.025^{*}$ \\
\hline & PBSC & 39 & -0.079 & 0.088 & 0.841 & 0.828 & & $0.033^{*}$ \\
\hline & $\mathrm{BM}$ & 10 & 0.864 & 0.171 & $0.016 *$ & $0.025 *$ & $0.033^{*}$ & \\
\hline
\end{tabular}

Table 2 


\begin{tabular}{|c|c|c|c|c|c|}
\hline Gene & Group & $\log R Q P A R P 1$ & $\log R Q P A R P 2$ & $\log R Q P A R P 3$ & $\log R Q T R P M 2$ \\
\hline $\log R Q P A R P 1$ & \multirow[t]{4}{*}{ AML } & & 0.489 & 0.541 & -0.564 \\
\hline $\log R Q P A R P 2$ & & 0.489 & & 0.301 & -0.075 \\
\hline $\log R Q P A R P 3$ & & 0.541 & 0.301 & & -0.201 \\
\hline $\log R Q T R P M 2$ & & -0.564 & -0.075 & -0.201 & \\
\hline $\log R Q P A R P 1$ & \multirow[t]{4}{*}{ PBMC } & & $0.965 *$ & $0.950 *$ & $0.890 *$ \\
\hline $\log R Q P A R P 2$ & & $0.965 *$ & & $0.991 *$ & $0.911 *$ \\
\hline $\log R Q P A R P 3$ & & $0.950 *$ & $0.991 *$ & & $0.951 *$ \\
\hline $\log R Q T R P M 2$ & & $0.890 *$ & $0.911 *$ & $0.951 *$ & \\
\hline $\log R Q P A R P 1$ & \multirow[t]{4}{*}{ PBSC } & & $0.778 *$ & $0.693^{*}$ & 0.284 \\
\hline $\log R Q P A R P 2$ & & $0.778 *$ & & $0.820 *$ & 0.236 \\
\hline $\log R Q P A R P 3$ & & $0.693^{*}$ & $0.820 *$ & & $0.398 *$ \\
\hline $\log R Q T R P M 2$ & & 0.284 & 0.236 & $0.398 *$ & \\
\hline $\log R Q P A R P 1$ & \multirow[t]{4}{*}{$\mathrm{BM}$} & & $0.929 *$ & 0.964* & $0.607^{*}$ \\
\hline $\log R Q P A R P 2$ & & $0.929 *$ & & $0.821 *$ & $0.571 *$ \\
\hline $\log R Q P A R P 3$ & & $0.964 *$ & $0.821 *$ & & $0.536 *$ \\
\hline $\log R Q T R P M 2$ & & $0.607 *$ & $0.571 *$ & $0.536 *$ & \\
\hline
\end{tabular}

Figures

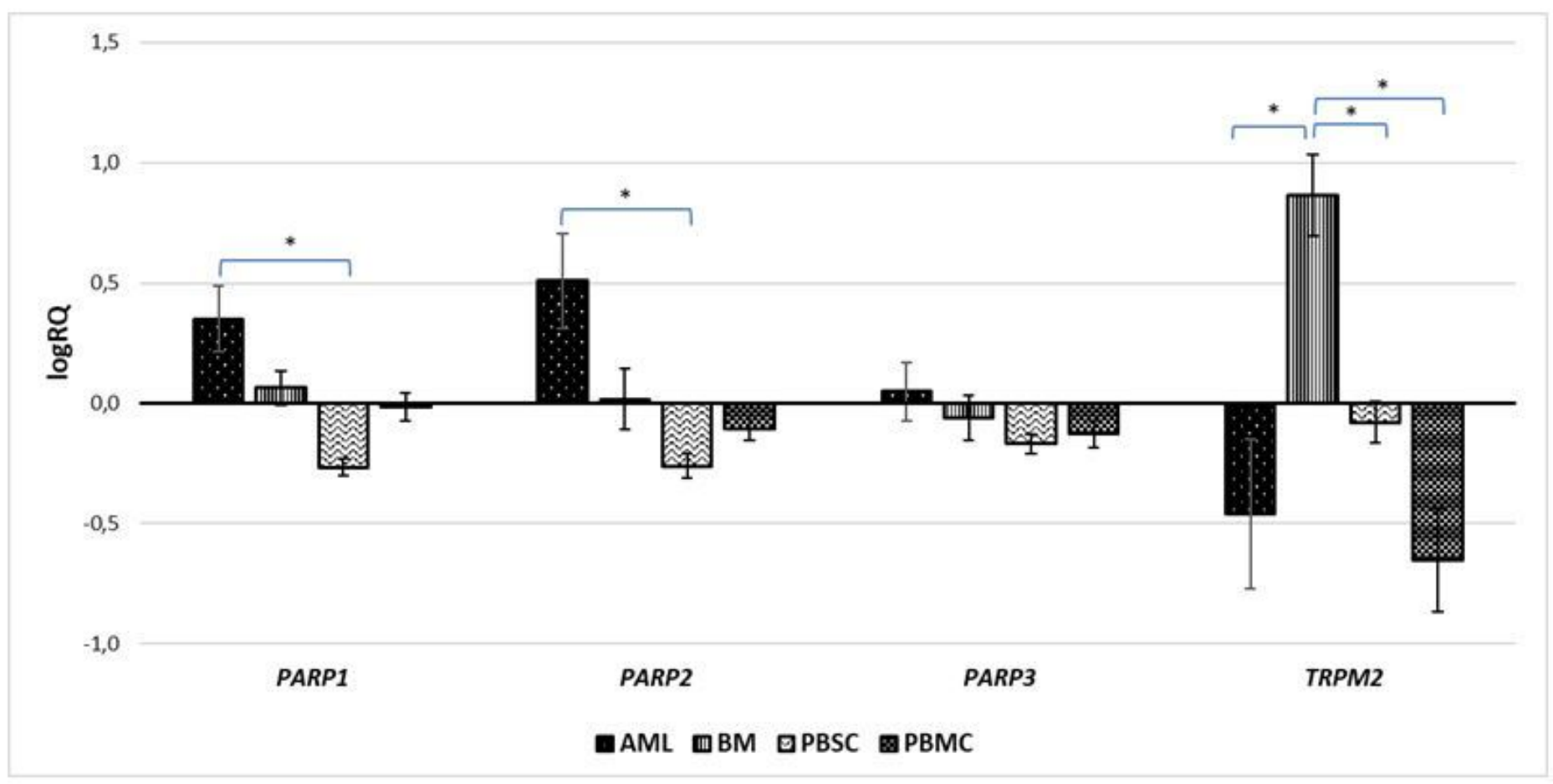

Figure 1

Mean PARP1, PARP2, PARP3 and TRPM2 gene expression (logRQ \pm SE) in groups of cells from the peripheral blood of healthy patients (PBMC), bone marrow of healthy patients (BM), bone marrow cells of 
acute myeloid leukemia (AML) patients and the peripheral blood stem cells after mobilization (PBSC), ${ }^{*} \mathrm{p}<0.05$ 